\title{
An Investigation into EFL Learners' Translations of Metaphors from Cognitive and Cultural Perspectives
}

\author{
Yi-chen Chen \\ Department of Foreign Languages and Applied Linguistics, Yuan Ze University, Taiwan
}

Received: 13-05-2017

Accepted: 14-06-2017

Published: 31-07-2017

doi:10.7575/aiac.ijclts.v.5n.3p.32

URL: http://dx.doi.org/10.7575/aiac.ijclts.v.5n.3p.32

\begin{abstract}
The study investigates how EFL learner-translators deal with metaphors and how cognitive factors and cultural background influence their choices. An English-to-Chinese translation task consisting of 20 English sentences was given to 70 Taiwanese university students; each sentence contains a figurative expression that falls into the categories in the cognitive cultural models (Kövecses, 2005). The students' performances on the task were rated; quantitative analyses show that the students performed significantly better on translating metaphors whose conceptual metaphors exist in both languages than on metaphors whose conceptual metaphors are exclusive to English. Additionally, twenty students were selected for post-task interviews; qualitative analyses indicate that sentence context, concerns over style and register, and translators' personal preferences affected their choices while translating. Communicative strategies, like providing neutral meanings to avoid uncertain translation, were adopted. The results contribute to the literature on and pedagogical applications for EFL learner translators from both cognitive and cultural aspects.
\end{abstract}

Keywords: Cognitive Linguistics, Conceptual Metaphor, Communicative Strategies, Translation, EFL

\section{Introduction}

Translation is considered to be a communicative approach whose function and role are different from the past. Not only is translation a major means of communication in most formal settings (Beeby-Lonsdale, 1996; Mezuláník, 2002), but in everyday life too, translation is considered to be an intermediary between cultures (Bernacka, 2012). Translation is a cross-language as well as a cross-cultural realization of communicative competence, serving various communicative purposes (Nord, 1997, 2006). Since, nowadays, the defined role of translation emphasizes its function and purpose for cross-language as well as cross-cultural communication, translators today should be more aware of how to deal with culture-bound expressions than they used to be. As a result, metaphor becomes a difficult area, 'a pain in the neck', for many translators.

Metaphor has long been considered a translation problem (Dobrzyńska, 1995; Schaffner, 2004), since its intended meaning does not coincide with the literal meaning of the words and sentences used (Glucksberg, 2001). No longer treated as simply literary decoration, metaphor is accepted as ordinary language that manifests what people think in daily life (Lakoff \& Johnson, 1980a). In other words, metaphor represents an inherent part of the culture that a speaker belongs to, and it is able to reflect the intangibles of a culture (Kövecses, 2005). For that reason, the translatability of metaphor is not a question of the equivalence of an individual expression between two languages at the literal level, but a matter of transferring a cultural embedment from one language to another at the conceptual level.

Such delicate interactions between languages and cultures during translation lead researchers to deem metaphor to be either not translatable at all (Dagut, 1976) or translatable only if it is modified and paraphrased (Newmark, 1981, 1988). Luckily, contemporary metaphor theory (Lakoff \& Johnson, 1980a; Kövecses, 2001) sees metaphor as a conceptual mapping and correspondence between a source conceptual domain as the tenor and a target conceptual domain as the vehicle; the theory is applicable to the field of metaphor translation, it suggests that by comprehending and analyzing the semantic motivations underpinning metaphors, a metaphor can be transferred to another language in another culture (Mandelblit, 1995; Kövecses, 2005; Al-Hasnawi, 2007). If translators can first detect the semantic motivation or conceptual metaphor of metaphorical expressions, and the similarities and differences between the source and target languages and cultures, they can provide proper translations or interpretations. On that basis, metaphor translation should become more approachable to translators.

But such a presumption also brings further challenges. Mandelblit (1995) found in his study with professional translators that a metaphor which has a different cognitive domain from the target language equivalent expression results in more delay and greater uncertainty in the translation process, due to the difficulty in finding an appropriate conceptual mapping and cognitive domain in the target language. Al-Hasnawi (2007) also reports a dilemma that professional translators face when translating religious metaphors whose images, or conceptual metaphors, are exclusively in Arabic and cannot be reproduced in the target language; then, professional translators have to either make an overall substitution or insert footnotes with additional explanations. In decisions dealing with such complex interactions between languages, cognition is linked to professional translators' competence and experience, which is not 
the case for novice translators, let alone learner-translators.

Though translation is believed to be an indispensable communicative tool, research on the work of L2 learnertranslators is scant. Regarding studies on translating metaphors, previous studies have focused on investigating linguistic features and the possibilities of translating metaphors from one language to another, but they have rarely investigated how learner-translators deal with metaphorical expressions. Therefore, the present study investigates how EFL learner-translators deal with metaphorical expressions from the perspectives of language and culture. The aim is to describe a cultural model for metaphor translation in an EFL context through instantiations and identify the strategies used and the problems faced by EFL learner-translators, and thus make pedagogical suggestions to learners and teachers who are devoted to cultivating such communicative competence.

\section{Literature Review}

\subsection{Metaphor in translation}

Translating a metaphorical expression means to transfer not only its linguistic form into another language, but also its cultural embedment into another culture. Problems thus occur due to concerns over the traditional equivalence-based concept in the discipline of translation studies (Dobrzynska, 1995; Schaffner, 2004). The concept of equivalence is meant to indicate that the source text (ST) and target text (TT) share some kind of "sameness" (Halverson, 1997). There is a question over the degree of sameness to which equivalence can extend. Many researchers (e.g. Catford, 1965; Koller, 1979; Newmark, 1981; Baker, 1992) propose different viewpoints to address the issue of equivalence. Catford (1965) refers to equivalence as substituting the ST with the TT at the linguistic level. Koller (1979), however, associates the concept of equivalence with the concept of correspondence, focusing not only on similarities but also differences between the ST and TT. Given these interpretations of the concept of equivalence, metaphor that is very culture-specific might hinder an intact transfer (Schaffner, 2004).

Rather than such a linguistic-based concept of equivalence, Newmark (1981) stresses semantic and communicative translation that aims to carry over the tone, meaning and rhetorical effect of the ST to the TT. Baker (1992) addresses the issue at various levels; among those, Baker claims that the primary aim of a translator should be to recreate the intended message in the ST in such a way that it becomes accessible and comprehensible to the target audience. Such prescriptive ideas about the concept of equivalence offer more options for interpreting and translating metaphorical expressions from one language to another.

Similar to Newmark's (1981) findings, Dobzynska (1995) proposes three possibilities for translating metaphor: a translator can use an exact equivalent of the original metaphor; a translator can look for another metaphorical phrase that expresses a similar sense; finally, a translator can replace an untranslatable metaphor in the original with an approximate literal paraphrase. Dobzynska uses a Polish translation of an Indian poem to examine these three possibilities and finds that all three have their limitations: an exact literal equivalent of a metaphor in the TT may not carry the same connotations assumed in the original text, though modifying and paraphrasing the original metaphor to adapt to the TT might lessen the semantic tension of the ST.

As Dobzynska (1995) concludes, the translation of metaphor presents not only lexical difficulties but also structural and textual ones. To go beyond the linguistic form and preserve the figurative sense, a cognitive approach to translation that links conceptual systems in the source and target cultures is proposed.

\subsection{Cognitive approach to translating metaphors}

The cognitive approach contributes to a new way to view translation. Cognitive linguistics assumes that language is an integral part of cognition (Lakoff, 1990). This idea opposes the traditional belief in the independence of cognitive processes from linguistic structures and rules. Moreover, instead of considering that the links between linguistic form and meaning are arbitrary, cognitive linguistics believes that language is motivated and grounded in bodily, physical and sociocultural experience (Johnson, 1987); in other words, language makes sense "under the constraints imposed by our bodies, through the culture sieve, and on the basis of our concrete experience" (Rojo \& Ibarretxe-Antuñano, 2013: 11). Thus, the idea of understanding a language embeds the ideas of knowing the culture and being aware of embodied experience. Hence, the emphasis of cognitive linguistics in translation redefines the role of a translator as an intercultural mediator between source and target texts; translation is no longer seen as a mechanical equivalence transfer between two linguistic systems, but rather as a communicative process in which linguistic and conceptual aspects are integrated (Rojo \& Ibarretxe-Antuñano, 2013).

By the same token, the cognitive approach to metaphor translation pays attention to the experiential and culture entailments embedded in metaphors. The approach to metaphor translation is rooted in the contemporary theory of metaphor proposed by Lakoff and Johnson (1980a). Opposing the traditional idea that metaphor is based on notions of similarity or comparison between literal and figurative meanings of an expression, the contemporary theory of metaphor considers metaphor to be a conceptual mechanism "by which we understand and structure one domain of experience in terms of another domain of a different kind" (Johnson, 1987: 15), it is a mapping of thoughts across different conceptual domains (Lakoff \& Johnson, 1980a). Each conceptual domain has its own inherent structures, called image schema, constructed from a cognitive typology of daily life experience (Lakoff, 1990). Metaphor can be explained and comprehended by analyzing the image schemata of two domains and matching corresponding traits. This corresponding mapping relationship between the source and target domains represents a conceptual metaphor, which covers the ontological correspondence between entities in a source domain and those in a target domain (Lakoff \& Johnson, 1980). In sum, a metaphor is formed on the basis of how a speaker conceptualizes the world. This viewpoint shifts the issue of 
metaphor translation from a purely surface and linguistic problem to a more internal and conceptual one (Mandelblit, 1995: 486); thus the translatability of metaphor is believed to reside in whether or not, and how, the conceptual systems in the source and target cultures associate with each other.

\subsection{Cognitive-cultural models of metaphor translation}

Models of metaphor translation that are affected by cultural variation have been proposed by various researchers (Mandelblit, 1995; Kövecses, 2005; Al-Hasnawi, 2007), and they have been found among a number of languages, such as English and Hungarian (Kövecses, 2001), English and German (Schaffner, 2004), English and Polish (Dobrzyńska, 1995), English and Hebrew (Mandelblit, 1995), English and Arabic (Al-Hasnawi, 2007) and English and Persian (Iranmanesh \& Kulwindr Kaur, 2010). These models and language data suggest that some metaphors are universal while others are culture-specific; translators need to identify the differences between the source and target languages, as well as the cultures, so that they can do proper translations and make correct interpretations.

Kövecses (2005), based on an analysis of Hungarian translation, proposes a thorough and systematic overview of the possibilities for transferring cultural- and cognitive-related metaphors from one language set and culture to another. As illustrated in Table 1, Kövecses adopts the idea of conceptual metaphors to the analysis, and he separates the meanings of translated form into literal and figurative meanings. This model clarifies some ambiguous terminology in previous models when referring to linguistic realizations: Mandelblit (1995) and Al-Hasnawi (2007) use the term lexical implementation to refer to the form of linguistic symbols along with the meaning of each symbol; however, the lexical forms must be different since they need two distinct languages to translate them, while the meanings conveyed through lexical forms can be the same or similar. Thus, Kövecses' (2005) model not only defines form and meaning more clearly, but also emphasizes semantic elements in a cognitive approach.

Table 1. Kövecses’ (2005) Model for translating metaphorical expressions

\begin{tabular}{lcccc}
\hline & Lexical & \multicolumn{2}{c}{ Meaning of Forms } & \multirow{2}{*}{$\begin{array}{c}\text { Conceptual } \\
\text { Fetaphors }\end{array}$} \\
\cline { 3 - 4 } & Forms & Literal & Figurative & Metaph \\
\hline Possibility 1 & Different & Same & Same & Same \\
Possibility 2 & Different & Different & Same & Same \\
Possibility 3 & Different & Different & Same & Different \\
Possibility 4 & Different & Different & Different & Different \\
\hline
\end{tabular}

Note. The table is based on Kövecses, 2005, pp.144, 149.

On the basis of a comparison between English and Hungarian, Kövecses (2005) finds that the first possibility, in which different word forms that are used have the same primary literal meanings, figurative meanings, and the same conceptual metaphor, is the most common case. The second possibility, in which the different word forms used have different primary literal meanings that are extended metaphorically within the same conceptual metaphor to yield the same figurative meanings, occurs less frequent than the first possibility. The third possibility, in which the same figurative meanings are expressed in different word forms that have different literal meanings within different conceptual metaphors, is the least frequent case compared with the other two possibilities. The fourth possibility, in which the expressions used in one language do not have exact counterparts in another language, is found in translated literature. Translators use expressions freely in order to make an integral whole of a literary work.

\subsection{Rationale and research questions}

The literature reviewed so far mainly focuses on finding patterns of translation between ST and TT metaphors, and offering explanations and elaborations of metaphor translations from a cultural perspective. But it is suggested by cognitive linguists that translation itself should be understood as cognitive interpretation by translators who bring SL meanings to TL texts, hence emphasis should be put on the decision-making procedures that translators go through in the course of formulating TT metaphors (Fuertes-Olivera \& Velasco-Sacristán, 2001), and the difficulties and problems that are faced should be identified to assist translators in making plausible choices of interpretations.

In EFL contexts in which translation is considered to be an important intermediary between languages and cultures, translation is viewed as the realization of communicative competence. In terms of helping EFL learners to become competent translators, pedagogical implications are important to facilitate learner translators making proper choices of interpretations that lead to proper translations. The research previously mentioned has used literary work or published editions as linguistic data for investigation, sources which are provided by professional translators who make translation their career and are acknowledged in publications; hence, the problems and difficulties that arise in the process of translating are not observable. Investigations targeting learner-translators should be conducted to gain insights into the decision-making processes in translation.

The present study aims to investigate how EFL learner translators deal with metaphors from the perspectives of cognition and culture. Kövecses' (2005) cognitive cultural model is adopted as the framework for the study. For one thing, Kövecses' model elaborates possible correspondences between two languages with respect to literal meanings, figurative meanings and conceptual metaphors, and thus it is more systematic when comparing with other models. For 
another, Kövecses' model has been used in Chinese EFL contexts (Chen \& Lai, 2014) to illustrate the characteristics of universality and specificity in metaphor. It is reasonable to presume that the model is the one that best matches the context of the present study.

The study is a semi-exploratory one that aims to investigate learners' performance from a new theoretical perspective. Three research questions are asked, as follows:

1. How do EFL learner-translators' translations of metaphor accord with or differ from those of cognitive cultural models of metaphor translation?

2. What strategies do EFL learner translators adopt in the process of translating to facilitate their decision-making?

3. What problems do EFL learner translators encounter, or what mistakes do EFL learner translators make, when translating culture-specific metaphorical expressions?

\section{Methodology}

\subsection{Participants}

An experiment was designed to include participants who meet the following criteria: first, in order to maintain a consistent general cultural background, participants were native speakers of Mandarin Chinese taking English as a foreign language; second, to define "learner-translators," participants were limited to enrolled university students in Taiwan. Most of them had taken introductory courses in translation or linguistics; some were from the College of Business and the College of Mass Communication and had general language training in college English courses. Thirdly, since the present study hypothesizes that cognitive similarities and cultural differences may influence learnertranslators' interpretations of metaphor, the study retains heterogeneity among the participants; more specifically, the participants in the study included males and females doing different academic majors. Personal information that might influence the formation of cognitive and cultural models, such as opportunities to be exposed to authentic English and familiarity with translation theories, was collected for reference.

In total, 70 Taiwanese university students participated in the present study, 23 females and 47 males. They were enrolled in different colleges and majoring in various fields, including English, Chinese, Mass Media and Communication, and Economics. They were 22 years old on average, with 15 years of English learning history, judging from the average age when they started learning English. Eighteen of the participants reported experience of living in an English-speaking country with an average duration of three months. Their duration of learning and exposure to English qualified them as EFL learners in the study. Their average English proficiency, according to reported scores on English proficiency tests, is estimated to be at the CEFR B2 level.

Twenty of the 70 participants were selected for post-test interviews. They were chosen to represent EFL learner translators with different educational backgrounds: four of them were master students on a programme for teaching Chinese as a second language, four were master students majoring in Linguistics, four were senior undergraduate students majoring in English, four were freshmen English majors, and four were non-English majors. Each group comprised two male and two female participants. The composition of a focus group sought to encompass general cases of EFL learners developing their competence in translation.

\subsection{Instrument}

A translation task (see Appendix 1) was developed to investigate how participants translate metaphorical expressions from English (ST, L2) into Chinese (TT, L1). Kövecses' (2005) model for translating metaphorical expressions was adopted as the framework for grouping a total of twenty English sentences into four categories; each category represents a possible pattern of correspondence between metaphors in the SL and TL.

Each category comprises five English sentences containing metaphorical expressions that represent a corresponding pattern. The metaphorical expressions were collected from previous studies (Lakoff \& Johnson, 1980; Lv \& Zhang, 2012; Yu, 2000, 2001, 2003) and have been demonstrated to be the same or different in English and Chinese. The target concepts of the metaphors, or tenors, include emotions (anger, happiness), concepts (life, time, love) and actions (control, know, do) etc.; the source concepts, or vehicles, include objects (game, money), body parts (finger, palm, face), animals (chicken) and so on. Sentences were selected to contain those metaphorical expressions and were collected from dictionaries and the Internet; these were reviewed and modified by a native English speaker to ensure their authenticity and grammatical accuracy.

Participants were asked to read each English sentence and then translate it into Chinese, they were asked not to consult dictionaries while doing so. If they encountered words or phrases that they could not understand, they were asked to mark the difficult parts and try to come up with translations that they considered were feasible. In other words, the participants needed to demonstrate their own ability to interpret metaphors instead of copying existing translated versions.

To analyze the participants' performance, the present study adopted a set of grading criteria used in previous studies (Chen \& Lai, 2014; Chen, 2015) and modified it to fit the purpose of the study. The criteria include three factors of the translation that can reflect a cognitive cultural model: meaning, form and comprehensiveness. The grading criteria of the study are as follows:

(5) The translation not only expresses the figurative meaning correctly, but also shows or relates to the conceptual metaphor exactly and precisely. 
(4) The translation expresses the figurative meaning correctly. The participant does NOT, however, seem to understand the conceptual metaphor, since his/her translation does not relate to the conceptual metaphor.

(3) The translation expresses an acceptable figurative meaning generally; the sentence is comprehensive in its figurative meaning.

(2) The translation expresses an acceptable sentence meaning literally.

(1) The translation is wrong.

(0) No answer.

\subsection{Procedure}

\subsubsection{Pre-study preparation}

Two research assistants were recruited and trained as the test raters for the quantitative part as well as interviewers for the qualitative part of the study. Both are native Chinese speakers with a bachelor's degree in English and have taken linguistic courses at universities which equipped them with general knowledge about linguistics and semantics. The two assistants were trained by the researcher in order to familiarize them with basic concepts of metaphor, and they were involved in two pilot studies to master the interview protocols and techniques as well as to ensure consistent agreements in their judgements.

\subsubsection{The study}

The study consists of two parts: implementation of the test and a post-test focus group interview. Before giving the test to the participants, an informed consent form and a personal information sheet were given to them for them to complete. Then, in both Chinese and English, the test instructions were read to the participants to ensure their full understanding of the test. No particular time limit was set, though the majority of the participants managed to complete the test within 30 minutes.

The participants who were selected for a focus-group interview still had individual interviews immediately after finishing the test. The trained assistants conducted the interviews in Chinese, following a retrospective think-aloud protocol, and asked the participants to describe how they translated each sentence. The assistants directed the participants' attention to the metaphorical expression in each sentence and guided the participants to recall how they made sense of those expressions and how they chose their ways of translating. The interviews were semi-structured; the interviewers were given a set of questions to ask and they were allowed to extend the conversation according to the responses of the participants. If the participants' translations were incorrect in terms of figurative meanings or different from correct English regarding conceptual metaphors, the assistants asked the participants to explain explicitly their ways of translating; the assistants also made suggested translation versions and allowed the participants to ponder the differences between their translations and the suggested ones. The interviews finished on average within 30 minutes.

\subsubsection{Post-study data analysis}

The data collected in the study include written answers from the translation test and recorded audio data from the interviews. Regarding the written answers, the two trained assistants individually graded the written test answers of all 70 participants. The researcher did not participate in the grading or interview processes in order to avoid possible bias from the researcher; only when the assistants had disagreements about their judgements did the researcher step in to join those discussions in order to reach a consensus.

Regarding the audio data from the interviews, these were transcribed to make written scripts for further analysis. In addition, the assistants' notes taken during the interviews were also taken into consideration as a reference of how the participants interpreted the metaphors. The researcher organized the interview scripts and looked for common or specific features of the focus group participants, including influential factors that contributed to the learner-translators' decision-making when translating metaphors. Then, the interview transcripts were coded to determine the strategies that the participants adopted for each category of metaphor.

\section{Results and Discussion}

\subsection{Qualitative Analysis}

To examine the performance of EFL learner-translators on interpreting and translating culture-based figurative expressions, i.e. metaphors, the researcher administered a translation test to 70 EFL university students. The completed tests were collected and graded by two trained raters. Inter-rater reliability was calculated to ensure that the grading of the 20 test items in the translation test was conducted consistently by them. Table 2 reports the results measured by a Spearman's rank correlation test. The correlation coefficient of the grades given by the two raters is $.926, p=.000$, which is significant at a 0.01 level with a 2-tailed hypothesis. The results indicate that the grades for all 20 test items given by the two raters are strongly correlated and demonstrate a high degree of consistency between them. 
Table 2. Correlation of Ratings

\begin{tabular}{lllll}
\hline & & Rater A & Rater B \\
\hline Spearman's rho & Rater A & Correlation Coefficient & 1.000 & $.926^{* *}$ \\
& & Sig. (2-tailed) & .000 \\
& $\mathrm{~N}$ & 20 & 20 \\
\cline { 2 - 5 } & Rater B & Correlation Coefficient & $.926^{* *}$ & 1.000 \\
& & Sig. (2-tailed) & .000 & \\
& $\mathrm{~N}$ & 20 & 20 \\
\hline$* * p<.001$, two-tailed. & & &
\end{tabular}

The 20 test items represent four possibilities for cross-cultural correspondence of figurative language. Each possibility contains five test items. Table 3 reports the results of mean scores for each possibility. Possibility 2 has the highest mean score $(\mathrm{M}=3.93, \mathrm{SD}=.77)$, followed by $\mathrm{P} 3(\mathrm{M}=3.71, \mathrm{SD}=.76), \mathrm{P} 1(\mathrm{M}=3.64, \mathrm{SD}=.34)$ and $\mathrm{P} 4(\mathrm{M}=2.91, \mathrm{SD}=.76)$. A one-way between subjects ANOVA test was conducted to compare the mean scores of the four possibilities. There are significant differences among the mean scores of the four possibilities at a $p<.05$ level, $F(3,36)=4.19, p=.01$. Post hoc comparisons using a Scheffe test indicate that the mean score for Possibility $2(\mathrm{M}=3.93, \mathrm{SD}=$. 77) is significantly higher than that of Possibility $4(\mathrm{M}=2.91, \mathrm{SD}=.76), p=.02<.05$.

The results of this post hot comparison imply a tendency that is consistent with the presumption that SL metaphors which are cognitively or culturally similar with TL correspondence should be easier for learner-translators to translate, while SL metaphors whose conceptual metaphors are exclusive should be more difficult. But the ranking of mean scores for the four possibilities indicates, however, that the participants were capable of doing more comprehensive translations of SL metaphors which were slightly different from the TL (i.e. P2 and P3) than of SL metaphors which should have corresponding metaphors in TL (i.e. P1). The reasons for this apparent contradiction of the presumption are discussed later in the qualitative analysis.

Table 3. Comparison of Grades for Four Possibilities

\begin{tabular}{lccccccc}
\hline & & & \multicolumn{3}{c}{$95 \%$ CI for M. } \\
Possibility & $N$. & $M$. & $S . D$. & Difference & $F(3,36)$ & $p$. & Test \\
\hline P 1 $(\mathrm{n}=5)$ & 10 & 3.64 & .34 & $(3.39,3.88)$ & 4.19 & $.01^{*}$ & P2>P4* \\
P 2 $(\mathrm{n}=5)$ & 10 & 3.93 & .77 & $(3.38,4.48)$ & & & \\
P 3 $(\mathrm{n}=5)$ & 10 & 3.71 & .76 & $(3.17,4.25)$ & & \\
P 4 (n=5) & 10 & 2.91 & .76 & $(3.30,3.79)$ & & \\
\hline
\end{tabular}

$* p<.05$, two-tailed.

Among the 70 participants, 20 were selected according to their educational backgrounds to form a focus group for posttest interviews. To ensure that the 20 selected participants did not differ significantly from the total sample, an independent-sample t-test was conducted. The results reported in Table 4 show that the mean scores for the 20 test items given to the 20 selected participants $(\mathrm{M}=3.43, \mathrm{SD}=.86)$ have no significant differences from those given to the other 50 participants in the study $(\mathrm{M}=3.59, \mathrm{SD}=.74), t(38)=.66, p=.51$. Therefore, these 20 participants' experiences of translating metaphors are regarded as typical with regard to determining how well EFL learner translators with similar backgrounds do when translating metaphors.

Table 4. Results of a T-test for the grades given to general and selected participants

\begin{tabular}{lccccccc}
\hline Participants & $N$. & $M$. & S.D. & $t$ & $d f$ & Sig. & $\begin{array}{c}\text { 95\% CI for } \\
\text { M. Difference }\end{array}$ \\
\hline General $(\mathrm{n}=50)$ & 20 & 3.59 & .74 & .66 & 38 & .51 & $(-.35, .68)$ \\
Selected $(\mathrm{n}=20)$ & 20 & 3.43 & .86 & & & & \\
\hline
\end{tabular}

\subsection{Qualitative Discussion}

4.2.1 Strategies that EFL learner-translators adopted while translating

The interviews of the 20 participants were transcribed into 1,140 sentences. These transcripts were analyzed and later coded to determine major factors. Six key strategies were identified. The frequency of occurrence of each factor is shown in Table 5. The most frequently mentioned factor that the participants took into consideration is the conceptual 
mapping of metaphor, following by contextual clues in the test sentences, personal preferences for expressions, memorized correspondence, appropriateness regarding genre style, and communicative strategies.

Table 5. Frequency of occurrence of six strategies

\begin{tabular}{lcc}
\hline Strategy & Frequency & Percentage \\
\hline Conceptual mappings & 432 & $37.9 \%$ \\
Contextual clues & 317 & $27.8 \%$ \\
Personal choice & 171 & $15.0 \%$ \\
Memorization & 133 & $11.7 \%$ \\
Register and formality of text & 50 & $4.4 \%$ \\
Communicative strategies & 37 & $3.2 \%$ \\
\hline Totals & 1,140 & $100 \%$ \\
\hline
\end{tabular}

When taking conceptual metaphors into consideration, the participants sometimes relied on the mental images created by metaphorical expressions. For instance, the participants made sense of the metaphorical expression grinned from ear to ear in Sentence Two by picturing the action of smiling from the left ear to the right one. A few participants even gestured a U-shape on their faces to illustrate such an action. Similar cases were found in kicked up their heels in Sentence Seven and knows ... like the back of his hand in Sentence Ten. However, such reliance on mental images could lead to imprecise interpretations. In Sentence Two, instead of interpreting the expression as smiling happily, two participants interpreted the action as secretly laughing and teasing other people, whereas one participant explained the action as passing secrets from one person to another.

In addition to the reliance on metal images, the participants mentioned using conceptual mappings to facilitate their interpretation process. In Sentence Fifteen, the metaphorical expression chickened out was understood by the participants through a conceptual mapping process. The participants elaborated their understanding of the animal chicken, and they projected the traits of a chicken onto the target to explain the sentence. In other words, the participants comprehended the SL metaphor through its conceptual metaphor. In translating Sentence Twelve, the participants related the traditional Chinese idiomatic expression 飄飄欲仙, “to float in the air like a fairy', to the English expression walking on air. The participants associated the TL conceptual metaphor with an SL metaphorical expression for an interpretation.

In addition to using conceptual mappings to facilitate interpretation, the participants also relied on the contexts of sentences to glean clues for SL metaphors. Contextual clues were particularly useful when the participants encountered unknown vocabulary. For instance, in Sentence One ("When he found out he was not going to be promoted, he gnashed his teeth"), the metaphorical expression gnashed his teeth was assumed to be understood easily since its conceptual metaphor is common in both Chinese and English and shares the same literal and figurative meaning. Yet many participants claimed uncertainty over the word gnash; they made sense of this sentence by interpreting the metaphor as the state of being angry based on the context created for the complete sentence. There is a similar case in Sentence Eighteen: "Many people go bananas during World Cup football games." The metaphorical expression go bananas was neither learned nor memorized by many participants. Thus they claimed they "guessed" by thinking about how people act during football games.

A third frequently mentioned strategy that affected or facilitated participants' translations was their personal preferences for narrating; more specifically, they took into consideration the adaptation of Chinese narrating style and expressions. In Sentence Four ("Shoppers are starting to lose their appetite for big supermarkets as online retailing becomes increasingly popular"), the participants mentioned their concerns over using a direct Chinese translation of the word appetite, 胃口 'a desire for food', to describe an abstract likeness existing in the market. They chose to interpret the term further and translated its figurative meaning in Chinese as 興趣 'excitement and interest'. Similarly, in Sentence Nine ("Years of teaching in a rigid education system have almost put out my passion for being a teacher"), the participants mentioned their concerns over using a direct Chinese translation of put out, 撲滅 'to make fire extinct', to describe passion. In this case, the participants preferred to use 澆熄, 'to throw cold water onto something', probably due to the fact that, in Chinese, extreme love is related to the concept of water, such as LOVE IS A FLUID IN A CONTAINER or LOVE IS A RIVER (Yang, 2008).

Memorization is a common strategy that EFL language learners use to facilitate their learning (Chen, 2010), and it is similarly found to be useful by learner-translators. The participants claimed that they had learned certain expressions before and memorized definitions. Thus they hardly hesitated to translate those expressions into Chinese. The metaphorical expression budget [your] time in Sentence Eight and was [so] touched by in Sentence Thirteen are examples. The participants even said that these expressions were too 直白, 'direct and simple', for them to need to ponder over a little longer. Interestingly, the expressions that they claimed they had memorized were translated accurately and got higher scores, suggesting that the participants took firmer decisions when memorizing Chinese correspondences. 
Compared to the above four strategies, the other two were less frequently mentioned in the interviews. Yet, these two strategies show that the participants also took potential readers' perspectives while translating. Regarding consideration of the register and formality of ST, few participants mentioned that they were afraid to make translations too colloquial to suit sentence contexts. For instance, in Sentence Eleven ("When you feel yourself getting ready to boil over with anger, get out and get some exercise"), one participant explained his translation of the metaphor boil over with anger into Chinese with 大發雷霆, 'to fly into a terrible rage', as he considered that the original English expression was an idiom and thus he chose a four-character Chinese idiom as its correspondence. Another participant said that she wanted to translate it into憤怒指數爆表, 'beyond the index of anger and become excessively angry', but he thought this Chinese expression was “too literal”; thus she decided to translate it as氣到要爆炸 "so angry that (the person) is about to explode'. The participants made their translation choices based on their ideas of what the TT should be like for the reader: if the TT would sound more formal or casual, seem like a literary work or a vernacular style, and so on.

Finally, the participants chose to use more neutral or vague terms when they were not certain how to translate something. When translating Sentence Twenty ("You will find that things happen much faster in hotels if you cross the staff's palms with silver often"), a participant claimed that she picked up and put together those words she knew as she did not understand the nart with the metanhorical exnression cross 「the staff's] nalms with silver: 你會發現如果你跳過員工那一層, 事情會更為有效率 'You will find that if you skip the staff you will be more efficient.' In Sentence Five ("The team lost their star nlaver last vear and didn't want to let another slin throuoh their finoers") one narticinant not knowino what slin throuoh 「thoirl finoors meant wrote 「 1 狺個隊伍「 1 “不想再有任何隊上的損失了 '[...] this team [...] did not want to have any loss' to avoid giving an exact interpretation of the metaphorical expressions; instead, she chose to write a general meaning for the sentence. In these two cases, the participants got a score of (2) from both raters, indicating that the raters considered such translations expressed only acceptable sentence meanings in a literal way.

4.2.2 Strategies that EFL learner-translators adopted in the cognitive cultural model

Further analysis of the strategies that the participants adopted when translating sentences belonging to the four possibilities of the Cognitive Cultural Model shows that, though six strategies were identified, some were particularly frequently used by the participants to deal with metaphors with different possibilities. As shown in Table 6, the adoption of conceptual mappings was the most frequently used strategy among the four possibilities; while the participants used this strategy equally frequent to translate sentences of P1 (35\%), P2 (36\%) and P4 (36\%), they seemed to use it rather more frequently for sentences of P3 (43\%). The use of contextual clues was second; however, among the four possibilities, P4 seemed to reply on contextual clues more (P4: 31\%) than the other three (P1: 29\%; P2: 26\%; P3: $21 \%$ ). The third frequently used strategy was different among the four possibilities: P1 and P4 adopted the strategy of personal choice (P1: 17\%; P4: 19\%), whereas P2 and P3 adopted the strategy of memorization (P2: 19\%; P3: 16\%).

Table 6. Frequency of occurrences of strategies used for the four possibilities

\begin{tabular}{lcccc}
\hline & Possibility 1 & Possibility 2 & Possibility 3 & Possibility 4 \\
\hline Conceptual mappings & $95(35 \%)$ & $103(36 \%)$ & $113(43 \%)$ & $117(36 \%)$ \\
Contextual clues & $69(26 \%)$ & $74(26 \%)$ & $56(21 \%)$ & $99(31 \%)$ \\
Personal choice & $53(20 \%)$ & $36(13 \%)$ & $29(11 \%)$ & $61(19 \%)$ \\
Memorization & $28(10 \%)$ & $54(19 \%)$ & $41(16 \%)$ & $23(7 \%)$ \\
Register and formality & $13(5 \%)$ & $9(3 \%)$ & $17(6 \%)$ & $12(4 \%)$ \\
Communicative strategies & $12(4 \%)$ & $9(3 \%)$ & $6(2 \%)$ & $11(3 \%)$ \\
\hline Totals (100\%) & 270 & 285 & 262 & 323 \\
\hline
\end{tabular}

The frequencies of adoption of strategies also elaborated the difficulties and problems the participants encountered when translating metaphors belonging to different possibilities in the cognitive cultural model. Metaphors belonging to P3 required the translators to express the same figurative meanings of ST in the TT, even though the literal meanings and conceptual metaphors are different in the TL. The participants claimed to make sense of SL conceptual metaphors through creating mental images by themselves or looking for appropriate TL conceptual metaphors. The metaphorical expression a [real] pain in the neck in Sentence Fourteen ("Joan is a real pain in the neck, with her constant complaining") was pictured as a thorn sticking in someone's neck, causing an unpleasant feeling for people; the participants interpreted the metaphor as trouble or an unhappy event, and looked for Chinese expressions with a similar figurative meaning; finally, they formulated the Chinese expression 麻煩人物, 'a trouble-maker', or 很煩人, 'be annoying'. This process of translation was repeated when translating Sentence Eleven, boils over [with anger], Sentence Twelve, [are] walking on air, and Sentence Fifteen, chicken out. But the metaphorical expression touched in Sentence Thirteen was indicated by the participants as being too commonly seen and used, hence they translated the metaphor into 感動, 'be emotionally moved', without uncertainty. 
Metaphors of P2 have corresponding figurative meanings and conceptual metaphors between SL and TL, the only difference is in their literal meanings. In addition to searching for and relying on shared conceptual metaphors, the participants claimed to count on their memorization frequently. The use of memorization has also been found in previous research (Chen, 2015; Lai \& Chen, 2010), in that EFL learners tended to pay special attention to expressions that were idiom-like, and they were more assertive in using them. In Taiwan, most textbooks on figurative language still rely on traditional rote learning, which requires L2 learners to memorize English figurative expressions, figurative meanings and sample sentence structures. In the present study, when the meanings of metaphorical expressions cannot be formulated from literal instantiations, such as P2 and P3 metaphors, the participants tended to look to their memorization for help.

The participants adopted contextual clues more frequently when translating metaphors of P4, metaphors that are different in their literal and figurative meanings, as well as conceptual metaphors. This tendency of use suggests greater difficulties for the participants when trying to make sense of each metaphor. These gaps between languages exist due to the different cognitive and cultural entailments. Thus the participants turned to sentence contexts for assistance. In contrast, the gaps were smaller, as when translating metaphors of P1, since these metaphors have corresponding expressions with similar cognitive and cultural entailments. Thus the participants paid more attention to choosing words or expressions to make their translations fluent.

\section{Pedagogical Implications}

The findings of the present study demonstrate the importance of the cognition and culture that underpin language. In addition to fundamental language skills training, priority should be given to raising EFL learners' awareness of the cognitive and cultural entailments of English expressions, and of the corresponding patterns between SL and TL. EFL teachers could start by introducing students to metaphors grounded in universal experience, such as embodiment. Metaphors that concern human emotions, for instance, are a good example to illustrate the close relation between bodily responses and conceptual metaphors. The conceptual metaphor ANGER IS HEATED FLUID IN A CONTAINER can be understood through language users' own experiences of their bodies as containers filled with various fluids (e.g. blood, sweat and tears) that can heat up when under pressure or feeling emotional in different ways. Then, EFL teachers could push further by guiding students to reflect on similar scenarios in another language, discuss similarities and differences, and finally establish image schemata of conceptual domains. Through schematizing conceptual domains, awareness of the corresponding patterns between languages and cultures can be specified, and the differences and similarities can also be explicitly indicated.

Secondly, EFL learner translators should be taught and trained to look for clues to interpretation. Such clues could be drawn from sentence contexts, mental images or even translators' own life experience. In order to cultivate learnertranslators' ability to seek clues, EFL teachers should help them to realize that translation in a globalized world focuses on the function and purpose of communication, and hence the ideal translation equivalence of ST and TT is defined by how well the TT is intelligible and comprehensible to the reader's eyes. Thus learner-translators should treat metaphor as part of a sentence or a bigger context, rather than a single and independent unit; the primary goal of translating metaphor should be to fit in with the whole of a sentence's meaning. Also, EFL learner-translators should be encouraged to use communication strategies in their translation, with the premise not to twist original meanings.

Finally and appropriately, EFL translators should be guided by what the audience wants the translated text for. Rather than giving interpretations directly, learner-translators should be guided to evaluate the implied meanings of metaphor, and to choose appropriate expressions to suit the context. Translators frequently face a dilemma: whether to formulate TT as literally as possible and leave the implied meaning for the reader to interpret themself, or to offer the most logical interpretation of a metaphor yet reveal too much implied information. As suggested by Newmark (1988), translators should identify the cause of comparison entailed in a metaphor and evaluate positive or negative colouring of the sense in this semantic area. Such ability requires guidance to recognize not only conceptual metaphors but also the cultural background of the language. Littlemore (2003) suggests that discussions and debates about metaphors should be conducted in classrooms to facilitate exploring the cultural values and assumptions that underpin them.

\section{Conclusion}

The present study has investigated how EFL translators interpret and translate English metaphors into Chinese. The cognitive cultural model is used to categorize metaphors via the cognitive and cultural correspondences between two languages. Through collecting translation data from learner translators, some difficulties and problems encountered by general EFL speakers in comprehending English metaphors were identified: while EFL learner-translators were able to use conceptual metaphors together with mental images to make sense of metaphorical expressions, they still counted on contextual clues and memorization to deal with metaphors which are cognitive and culturally exclusive. Moreover, the EFL learner-translators claimed additional difficulty in choosing appropriate expressions to fit the register or formality of a translation text. The results of the study contribute to the literature on EFL learners' interlanguage development from both linguistic and cultural aspects, as well as to the promotion of pedagogical applications for EFL learnertranslators.

The present study is not without its limitations. It targets translating in one direction, i.e. translating from English (L2) to Chinese (L1). Whether EFL learner translators would encounter similar problems when translating from Chinese (L1) to English (L2) is unknown. Moreover, whether they would use strategies is also worth further investigation. Furthermore, the present study does not examine the possible influence of EFL learner translators' background, gender 
or personal profile on their translations. Since metaphor is related to a language user's world view, their life experience should influence their interpretations of meanings, going beyond words.

In future studies, metaphor translation should be investigated in both directions: L2 to L1, and L1 to L2. Except for taking learner-translators' profiles into consideration, how professional translators deal with metaphor translation is worthy of exploration.

\section{References}

Al-Hasnawi, A. R. (2007). A cognitive approach to translating metaphors. Translation Journal, 11(3). Retrieved November 13, 2013, from http://www.bokorlang.com/journal/41metaphor.htm

Baker, M. (1992). In other words: A coursebook on translation. London: Routledge.

Beeby-Lonsdale, A. (1996). Teaching translation from Spanish to English: Worlds beyond words. Canada: University of Ottawa Press. Retrieved November 18, 2013, from http://www.ruor.uottawa.ca/en/handle/10393/12957

Bernacka, A (2012) The importance of translation studies for development education. Policy \& Practice: A Development Education Review, 14 (1), 113-118.

Catford, J.C. (1965). A linguistic theory of translation. London: Oxford University Press.

Chen (2010). The Effects of Teaching EFL Learners Metaphor and Metonymy: With Reference to Emotion Expressions. Unpublished doctoral dissertation. National Chengchi University.

Chen, Y. (2015). An Investigation of EFL Learners' Cultural Awareness of Universality and Specificity of Figurative Language. Linguistics, Culture \& Education, 2015(2015), Article ID3. Retrieved October 1 ${ }^{\text {st }}, 2015$, from http://scik.org/index.php/lce/article/view/2117/1143

Chen, Y. \& Lai, H. (2014). The influence of cultural universality and specificity on EFL learners' comprehension of metaphor and metonymy. International Journal of Applied Linguistics. doi: 10.1111/ijal.1202

Colina, S. (2003). Translation teaching, from research to the classroom: A handbook for teachers. Boston: McGrawHill.

Dagut, M. (1976). Can metaphor be translated? Babel: International Journal of Translation, 12(1), 21-33.

Duff, A. (1989). Translation. Oxford: Oxford University Press.

Dobrzynska, T. (1995). Translating metaphor: Problems of meaning. Journal of Pragmatics, 24 (6), $597-603$.

Fuertes-Olivera, P. A., \& Velasco-Sacristán, M. (2001). The translatability of metaphor in LSP: Application of a decision-making model. Revista Alicantina de Estudios Ingleses, 14, 73-91. Retrieved October 1 15, 2015, from http://rua.ua.es/dspace/bitstream/10045/5285/1/RAEI_14_05.pdf

Glucksberg, S. (2001). Understanding figurative language: From metaphors to idioms. New York: Oxford University Press.

Halverson, S. L. (1997). The concept of equivalence in translation studies. Target, 9(2), 207-233. Retrieved November 27, 2013, from http://www.itcanet.ir/ITCA/Articles/Translation/The\%20Concept $\% 20$ of $\% 20$ Equivalence\%20in $\% 20$ Translation $\% 20$ Stu dies.pdf

Howatt, A. P. R., \& Widdowson, H. G. (2004). A history of English language teaching. Oxford: Oxford University Press.

Huang, K. S., \& Wang, T. P. (2011). An investigation of students' attitudes to the utilization of the communicative translation teaching (CTT) in college English translation classrooms. The Journal of Global Business Management, 7(2), 204-211. Retrieved November 27, 2013, from http:/www.jgbm.org/page/22\%20Kuo-shu\%20Huang.pdf

Hymes, D.H. (1972). On communicative competence. In J.B. Pride, \& J. Holmes (Eds.), Sociolinguistics (pp.269-293). Harmondsworth: Penguin Books.

Iranmanesh, A., \& Kulwindr Kaur, G. S. (2010). A cognitive approach and the translation strategies used in the subtitling of metaphors in three American movies. In L. S. Teip, R. T. Bell, B. Templer, O. Steinmayer, \& A. R. M. Zaid (Eds.), Proceedings of the International Conference on Translation and Multiculturalism: Found in Translation a common voice in a multicultural world. Kuala Lumpur, Malaysia: University of Malaya. Retrieved November 18, 2013, from http://english.um.edu.my/anuvaada/PAPERS/IRANMANESH.pdf

Johnson, M. (1987). The body in the mind: The bodily basis of meaning, imagination, and reason. Chicago: Chicago University Press.

Kiraly, D. C. (2000). A social constructivist approach to translator education. Manchester, UK: St. Jerome.

Koller, W. (1995). The concept of equivalence and the object of translation studies. Target, 7(2), 191-222. http://dx.doi.org/10.1075/target.7.2.02kol

Kövecses, Z. (2001). A cognitive linguistic view of learning idioms in an FLT context. In M. Pütz, S. Niemeier, \& R. Dirven (Eds.), Applied cognitive linguistics II: Language pedagogy (pp. 87-115). Berlin: Mouton de Gruyter. 
Kövecses, Z. (2005). Metaphor in culture: Universality and variation. Cambridge, U.K.; New York: Cambridge University Press.

Lai, Huei-ling, \& Chen, Yi-chen (2010, April 15-17). The effects of EFL learners' application of metaphor and metonymy in learning and retaining emotion expressions. Paper presented at the 2010 International Conference on Applied Linguistics \& Language Teaching (ALLT). National Taiwan University of Science and Technology, Taipei, Taiwan.

Lakoff, G. (1990). The invariance hypothesis: Is abstract reason based on image-schema? Cognitive Linguistics, 1(1), 39-74. Retrieved November 27, 2013, from http://georgelakoff.files.wordpress.com/2011/04/the-invariance-hypothesisin-cognitive-linguistics-11-lakoff-1990.pdf

Lakoff, G., \& Johnson, M. (1980a). Metaphors we live by. Chicago: University of Chicago Press.

Littlemore, J. (2003). The effect of cultural background on metaphor interpretation. Metaphor and Symbol, 18(4), 273288.

Lv, Z. \& Zhang, Y. (2012). Universality and variation of conceptual metaphor of love in Chinese and English. Theory and practice in language studies, 2(2), 355-359.

Mandelblit, N. (1995). The cognitive view of metaphor and its implications for translation theory. In M. Thalen, \& B. Lewandowska-Tomasczyk (Eds.), Translation and Meaning. Part 3 (pp.482-495). Maastricht: Maastrich UP.

Marqués Aguado, T., \& Solís-Becerra, J. (2013). An overview of translation in language teaching methods: Implications for EFL in secondary education in the region of Murcia. Revista de Lingüistica y Lenguas Aplicadas, 8(1), 38-48. http://dx.doi.org/10.4995/rlyla.2013.1161

Mezuláník, J. (2002). Globalisation and its impacts on business communication. In D. Köksal, J. Mezuláník, \& S. Polouček (Eds) Challenges for Business Administrators in the new Millennium. Canakkale, Turkey: Canakkale Onsekiz Mart University. Retrieved Nov. 11, 2013, from http://www.opf.slu.cz/vvr/akce/turecko/pdf/Mezulanik.pdf

Newmark, P. (1981). Approaches to Translation. Oxford: Pergamon Press.

Newmark, P. (1988). A Textbook on Translation. New York: Prentice Hall,

Nord, C. (1997). Translating as a purposeful activity: Functionalist approach explained. Manchester: St. Jerome.

Nord, C. (2006). Translation as a purposeful activity: A prospective approach. TEFLIN Journal, 17(2), 131-143. http://dx.doi.org/10.15639/teflinjournal.v17i2/138-151

Park, G. (1995). The role of translation in the communicative approach. Miscellanea, 2, 239-246. Retrieved November 26, 2013, from http://www.openstarts.units.it/dspace/bitstream/10077/7676/1/Parks_miscellanea_2.pdf

Pavan, E. (2013). The Simpsons: Translation and language teaching in an EFL class. Studies in Second Language Learning and Teaching, 3(1), 131-145.

Rojo, A., \& Ibarretxe-Antunano, I. (2013). Cognitive linguistics and translation studies: Past, Present and Future. In A. Rojo, \& I. Ibarretxe-Antunano (Eds), Cognitive linguistics and translation: Advance in some theoretical models and applications (pp.1-30). Berlin, New York: Mouton de Gryuter.

Schaffner, C. (2004). Metaphor and translation: Some implications of a cognitive approach. Journal of Pragmatics, 36(7), 1253-1269. https://doi.org/10.1016/j.pragma.2003.10.012

Tudor, I. (1987). Using translation in ESP. ELT Journal 41(4), 268-273. https://doi.org/10.1093/elt/41.4.268

Yang, R. (2008). A holographic study of metaphors concerning love in Chinese. Intercultural Communication Studies, 17, 90-101. Retrieved October 3 ${ }^{\text {rd }}$, 2015, from http://web.uri.edu/iaics/files/10-Renying-Yang.pdf

$\mathrm{Yu}$, N. (2000). Figurative uses of finger and palm in Chinese and English. Metaphor and Symbol, 15(3), 159-175.

Yu, N. (2001). What does our face mean to us? Pragmatics \& Cognition, 9(1), 1-36.

Yu, N. (2003). Chinese metaphors of thinking. Cognitive Linguistics, 14(2/3), 141-165.

\section{Appendix}

Research Instrument: Translation Task

1. When he found out he was not going to be promoted, he gnashed his teeth.

2. The chief grinned from ear to ear as he read the latest restaurant review on the newspaper.

3. How can I advance in my career when my competitor holds all the aces?

4. Shoppers start to lose appetite for big supermarkets with online retailing becoming increasingly popular.

5. The team lost their star player last year, and didn't want to let another slip through their fingers.

6. He was upset, and your making fun of him just added fuel to the fire.

7. After the exam, students kicked up their heels and had a really good party.

8. The best way to budget your time well is to start by keeping track of what you do during the day. 
9. Years of teaching in a rigid education system have almost put out my passion for being a teacher.

10. He knows the software like the back of his hand, and can solve problems over the phone without looking.

11. When you feel yourself getting ready to boil over with anger, get out and get some exercise.

12. Most couples feel they are walking on air on their wedding day.

13. I was so touched by his stories that I bought his autobiography immediately.

14. Joan is a real pain in the neck, with her constant complaining.

15. He promised to try bungee jumping with me, but at the last minute he chickened out.

16. Supporters stormed out of the meeting place when they found out their candidate lost the election.

17. The conversation with my friend was nice, and her kind words really gave me a lift.

18. Many people go bananas during the World Cup football games.

19. Tess always wants to have a finger in the pie because she doesn't think we can do it by ourselves

20. You will find that things happen much faster in hotels if you cross the staff's palms with silver often. 